\title{
Proceedings
}

\section{Evaluation of wood chipping efficiency through long-term monitoring}

\author{
Alberto Cadei ${ }^{1{ }^{*},}$, Luca Marchi ${ }^{1}$, Omar Mologni $^{2}$, Raffaele Cavalli ${ }^{1}$ and Stefano Grigolato ${ }^{1}$ \\ 1 Department of Land, Environment, Agriculture and Forestry, Università degli Studi di Padova, Viale dell’Università 16, \\ 35020 Legnaro, Padova, Italy; luca.marchi@unipd.it (L.M.); raffaele.cavalli@unipd.it (R.C.); stefano.grigolato@unipd.it \\ (S.G.); \\ 2 Department of Forest Resources Management, Faculty of Forestry, The University of British Columbia, MainMall 2424, \\ Vancouver, BC V6T 1Z4, Canada; omar.mologni@ubc.ca (O.M.); \\ * Correspondence: alberto.cadei@phd.unipd.it (A.C.); \\ † Presented at the 1st International Electronic Conference on Forests, 15-30 November 2020; \\ Available online: https://sciforum.net/conference/IECF2020
}

\begin{abstract}
High volume of wood forest biomass can be available at roadside when whole three (WT) harvesting system is applied. Besides, salvage logging operations are favourable conditions to accumulate a large amount of low-quality biomass due to the recovery of damaged trees. In mountain regions, such as the Alps, the forest accessibility can be a significant constraint for the eco-efficiency of chipping operations. The present study aims at evaluating the efficiency of wood-chipping operations in mountain areas based on long-term monitoring. One chipper-truck was monitored during 1200 working hours using telemetry; different efficiency parameters were collected: machine position, collected using GNSS receiver, and engine parameters, collected using CAN Bus system based on J 1939. Efficiency parameters were used to compare different in-wood or landing configurations. The results show the influence of the different location of the chipping sites according to the road network. Chipping operations in space-constrained sites cause an increase in delay time and $\mathrm{CO}_{2}$ emissions.
\end{abstract}

Keywords: Telemetry; Efficiency; Biomass; Residues; Emissions.

\section{Introduction}

Due to climate change, the production of energy from renewable sources has increased in recent years [1]. Because of climate neutrality 2050 EU goal [2], the European Commission is planning to reduce EU greenhouse gas (GHG) emission by at least $55 \%$ by 2030 . In these situations, the energy used for producing energy from renewable sources needs to be optimised. Product made by biomass is typically considered low impact product in term of GHG emission compared to the equivalent product made from non-renewable sources [3].

The primary products from forestry and logging are industrial roundwood and fuelwood, in Italy about four-fifths of its roundwood production was provided as fuelwood [4]. Typically, after timber harvesting, a large quantity of low-quality biomass (LQB) such as non-commercial timber and logging residues are left on site. In the last years, the demand for LQB as feedstock for renewable energy is increased. Therefore, resource efficiency and GHG emission from the forestry sector can be optimised by encouraging cascading biomass use [5]. In fact, after the merchantable timber harvester, LQB can be collected and chipped at roadside landing or terminals [6]. However, in order to increase the efficiency in recovery LQB, all the processes involved in the biomass supply chain need to be considered [7].

Typically, whole-tree (WT) harvesting system provides higher volume of logging residues compared to cutto-length (CTL) harvesting system where branches and unmerchantable top sections of trees are left in the cutting area [8]. Also, the harvesting treatment affects the quantity of wood chips yields: clear cuts in low-quality stand can generate a large quantity of biomass as well as salvage logging operations[9], on the contrary, whole tree chipping in early thinning operation generate a lower quantity of fuelwood [10]. Consequently, accumulated fuelwood can be chipped at the roadside landing or transported at the terminals [11]. Chipping at the roadside is less cost-effective than chipping at the terminals [12], besides, in mountain regions, such as the Alps, the forest accessibility can be a significant constraint for the eco-efficiency of chipping operations. When truck and trailer or 
semitrailer are unable to reach working sites, chips can be shuttled outside forest with truck or tractor and trailer units [13]. Also, when the yarding contractor does not coincide with chipping contractor, some problems may arise [13]. Good cooperation between yarding contractors and chipping contractors, in order to identify in advance the location for piling logging residues, can improve the efficiency of the chipping activity (e.g. no stones or metal in the pile) and reduce the frequency of the relocation (e.g. number and dimension of logging residues piles)[14]. Using modern technology is possible to improve the economic, environmental and social sustainability of forest operation [15].

Modern device based on data transmission via GPRS-UMTS-HSDPA connections can be used to easily monitor and collect data of the entire wood chip production [16] as also proposed by Holzleitner et al. [17] using fleet management system (FMS) monitoring chipping and transport activities.

This study based on semi-automated method aims at evaluating the efficiency of wood chipping through long term monitoring based on FMS. More specific goals were to evaluate the efficiency and $\mathrm{CO}_{2}$ equivalent emission of wood chipping activity in mountain areas and to evaluate the effect of the accessibility to the working site on the efficiency and $\mathrm{CO}_{2}$ emission.

\section{Materials and Methods}

\subsection{Wood chipper details}

The chipper-truck was based on chipper unit, a Mus-Max Wood Terminator 10 XL, mounted on a three-axles MAN truck, a MAN TGS-28.540. 397 kW truck's engine powered the chipper unit. Chipping operations were carried out by the operators from the external cabin (Figure 1). Net productivity declared by the manufacturer is $180 \mathrm{~m}^{3} / \mathrm{h}$. Details of the machine are reported in Table 1.

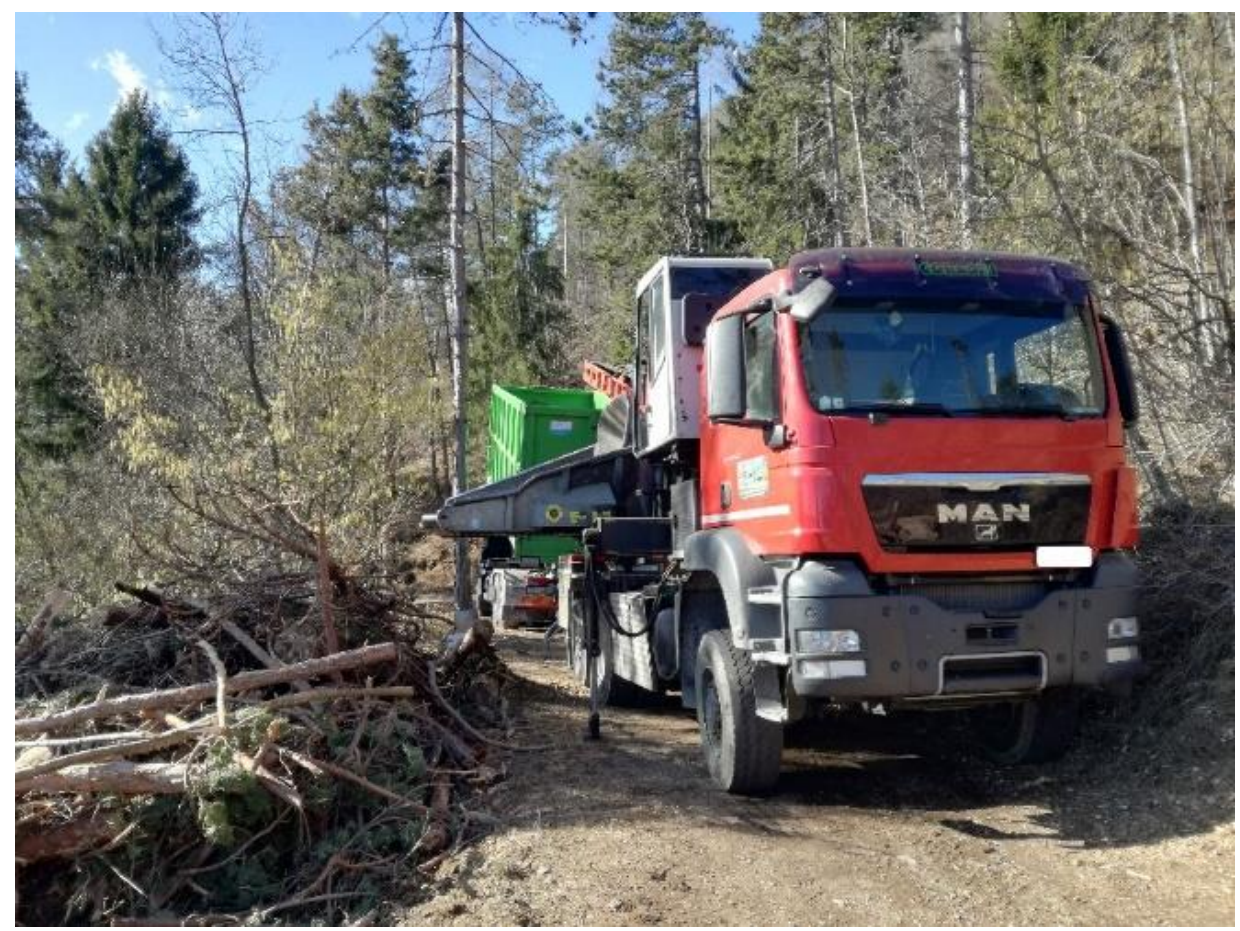

Figure 1. - Mus-Max Wood Terminator 10 XL chipper truck.

Table 1. Detail of Mus-Max 10 Wood Terminator XL chipper-truck.

\begin{tabular}{ccc}
\hline Truck & & \\
\hline Manufacturer & - & MAN \\
Model & - & Man TGS 28.540 \\
Engine type & - & Man 6 cylinders \\
Engine power & $\mathrm{kW}$ & 397 \\
\hline Chipper unit & & \\
\hline
\end{tabular}




\begin{tabular}{ccc}
\hline Manufacturer & - & Mus-Max \\
Model & - & Wood-Terminator 10 XL \\
Feed opening & $(\mathrm{w} \times \mathrm{h}) \mathrm{mm}$ & $980 \times 750$ \\
Tree diameter max & $\mathrm{mm}$ & 750 \\
Drum diameter & $\mathrm{mm}$ & 900 \\
Chopping knives & $\mathrm{n}^{\circ}$ & 12 \\
\hline Crane & & \\
\hline Model & & Penz 14 L \\
Gross lifting torque & $\mathrm{kNm}$ & 136 \\
Maximum boom reach & $\mathrm{m}$ & 10.1 \\
\hline Chipper-truck & & \\
\hline Weight & $\mathrm{kg}$ & 27000 \\
Length & $\mathrm{m}$ & 9 \\
Width & $\mathrm{m}$ & 2.5 \\
\hline
\end{tabular}

\subsection{Data collection and analysis}

This unit was equipped with GSM/GNSS Teltonika FM3612 receiver in order to collect Can-BUS data and machine position. Data were recorded from January 2019 to May 2020 with an acquisition rate set at $1 \mathrm{~Hz}$, as proposed by a similar study [17]. The web-server application for the acquisition of the data remotely was specifically developed for the study by Transpobank s.r.l. The data, downloaded from the server, include the following information: date-time stamp, position, altitude $(\mathrm{m})$, speed $(\mathrm{km} / \mathrm{h})$, engine temperature $\left({ }^{\circ} \mathrm{C}\right)$, engine hours, engine speed (rpm), total fuel used (l) and odometer (m).

In order to detect working site and information related to the road characteristics, the position of the machine was linked with the regional and provincial road database of Lombardia, Veneto and Trentino-Alto Adige The accessibility of chipping sites was derived with respect to the public road and forest road classification: primary state and regional public roads (Easy condition), secondary public roads and main truck forest roads (Moderate condition) and secondary truck forest roads with few sites where the trucks can turn (Difficult condition).

A dedicated $\mathrm{R}$ code was developed for time and motion study analysis based on cycle level [18] considering chipper position, chipper speed, engine speed and their combinations to detect the following work elements:

- chipping (C): when speed is under $1 \mathrm{~km} / \mathrm{h}$ and engine speed is above $1500 \mathrm{rpm}$;

- travelling (T): when speed exceeds $1 \mathrm{~km} / \mathrm{h}$ and engine speed is above $0 \mathrm{rpm}$;

- operational delay (OD): when speed is below $1 \mathrm{~km} / \mathrm{h}$ and engine speed is below $1500 \mathrm{rpm}$;

- non-operational delay and other delays (NOD): when engine (rpm) and chipper speed $(\mathrm{km} / \mathrm{h})$ are equal to 0 .

The observation units were the working sites which started with the first chipping element and finished with the end of the last one. The operator was instructed to record the chipping volume produced for in all the working sites separately.

\subsection{Efficiency calculation and statistical analysis}

In order to evaluate the efficiency of wood chipping operation, the following equation was used:

$$
\text { Efficiency }(\%)=\left(\frac{C}{C+T+O D+N O D}\right) * 100
$$

Environmental impact of wood chipping was evaluated in term of total $\mathrm{CO}_{2}$ equivalent emission $\left(\mathrm{kg} \mathrm{CO}_{2} \mathrm{eq}\right)$ in the different working sites taking in consideration the emission derived from all the work elements per working sites ( $T, C$ and OD). As proposed by De la Fuente et al. [12], fuel consumption (l) was converted into $\mathrm{CO}_{2}$ eq using emission factors per liter of fossil diesel fuel of $2.61 \mathrm{~kg} \mathrm{CO} 2 \mathrm{eq}$

Afterwards, all the data were analysed with working site as observational unit and classified per type of accessibility as defined before. The coefficient of determination $\left(R^{2}\right)$ was used to evaluate the goodness of fit of the linear model. The significance level of the statistical analysis was set to 0.05 . In case of non-normal distribution of the residual, square root and logarithmic transformation were tested on both dependent variable and independent variables. 


\section{Results}

The total working days were 168 , and the chipping activities were divided into 288 different working sites. Working activities in the different working sites covered over 1200 hours, 127 working sites $(399 \mathrm{~h})$ of these were registered in easy conditions, while 126 working sites $(494 \mathrm{~h})$ and 35 working sites ( $307 \mathrm{~h})$ were recorded in moderate and difficult conditions respectively.

As shown in Figure 2a net productivity, evaluate in terms of total volume (cubic meters of loose chips produced) during chipping activity, was higher in easy and moderate accessibility, on average $85.71 \mathrm{~m}^{3} / \mathrm{h}$ and $81.10 \mathrm{~m}^{3} / \mathrm{h}$ respectively, and lower in difficult condition, on average $38.35 \mathrm{~m}^{3} / \mathrm{h}$. Efficiency in difficult condition (Figure $2 \mathrm{~b}$ ) was $10 \%$ lower than moderate condition and $7 \%$ lower than easy condition. On average efficiency were $67.91 \%, 70.91 \%$ and $60.97 \%$ respectively in easy, moderate and difficult condition of accessibility. Higher efficiency, close to $100 \%$, was recorded in both easy and moderate conditions.

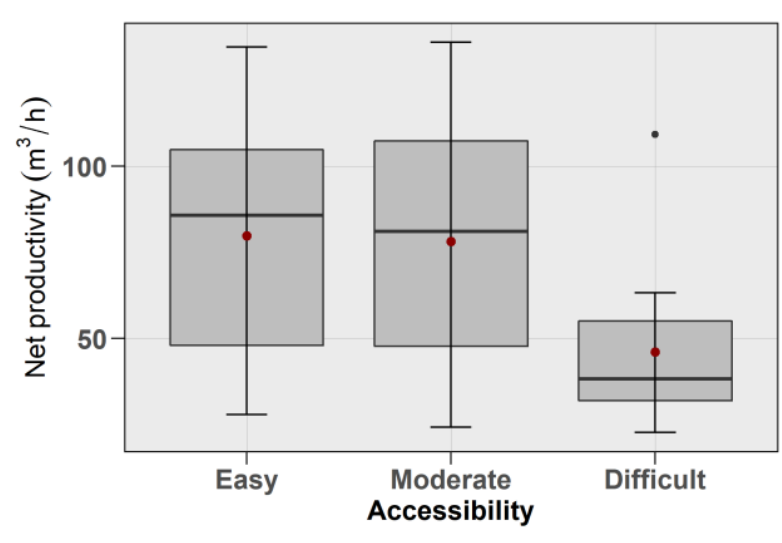

(a)

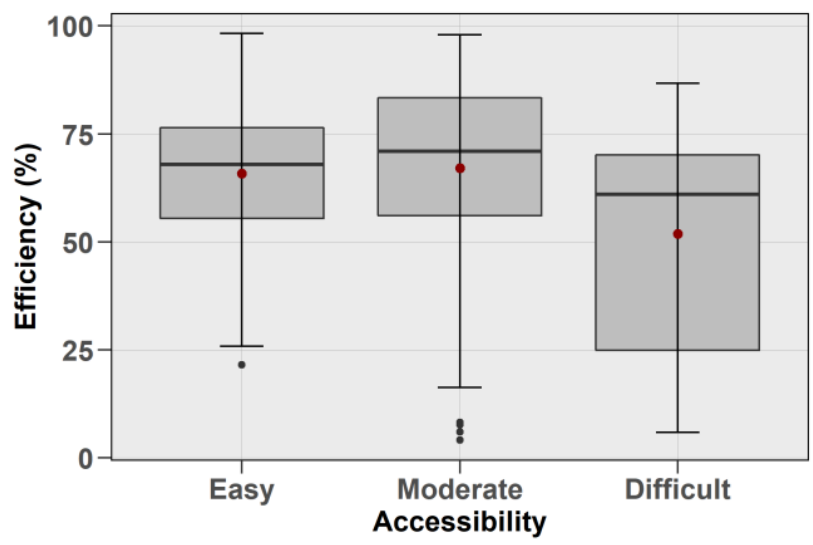

(b)

Figure 2 - Variability of net productivity in cubic meters of loose chips produced per hour (a) and chipping efficiency considering all the operational and non-operational activity (b) classified by accessibility of the working site. The boxes include the variability of the data between the 25th and the 75th percentiles. The horizontal black line represents the median while the circle in dark red represent the mean

Highest efficiency is related to the working sites where NOD and travelling elements were not recorded probably due to working sites located at the terminal. As reported in Table 2, OD and NOD increase when the difficulty in the accessibility increases. Besides, time travelling inside working sites increase from easy to difficult accessibility. The frequent relocation could explain the higher value of time travelling and travel distance in difficult condition of accessibility. As expected, travelling fuel consumption was higher in difficult working site than in easy and moderate. This confirms, with the hight time travelling in difficult condition, the challenging task to chip in mountain areas.

Chipped volume and different accessibility to working sites significantly affect the total emission produced $\left(\mathrm{R}^{2}=0.43, \mathrm{p}<0.001\right)$. In particular, as reported in Figure 3, the predicted total emission $\left(\mathrm{kg} \mathrm{CO}_{2} \mathrm{eq}\right)$ was higher in difficult condition $\left(1.25^{*}\right.$ volume chipped) than in easy one $\left(0.61^{*}\right.$ volume chipped) or moderate condition $\left(0.72^{*}\right.$ volume chipped). 
Table 2. - Descriptive statistics for time and fuel consumption based on Can-BUS system. OD: operational delay; NOD: non-operational delay.

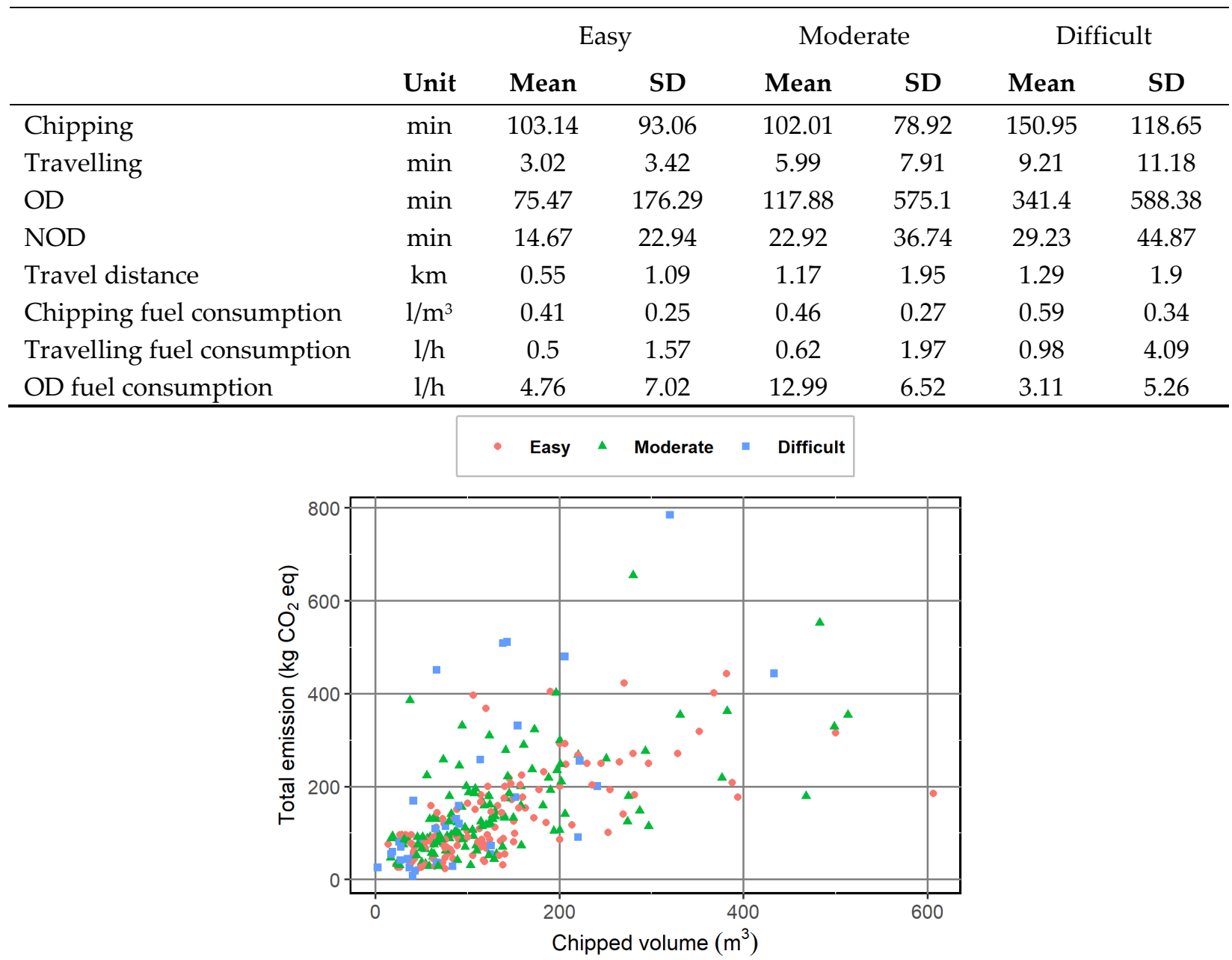

Figure 3. - Total emission per working sites with the respect of chipped volume (cubic meters of loose chips produced) and accessibility.

\section{Discussion}

Time consumption of chipping operation and total emission in different working site classified by different conditions of accessibility was analysed. Similarly, Holzleitner et al. [17] used the FMS and semi-automated method to monitor the supply processes of forest fuels. In this study, the data were analysed with the working site as observational unit. Isolating working activity, and related activity (travelling in working site, OD and NOD), our results show the effect of the accessibility on the efficiency and emission. Chipping activities in easy conditions, along primary public road, were the most effective method in term of net productivity and total emission produced during all the operations (chipping, travelling and idle time while the engine is running). Chipping in mountainous conditions, especially with difficult accessibility and poor quality of road infrastructures, is a hard challenge and could lead to a decrease in efficiency of about $7-10 \%$ compared to easy and moderate condition. Besides, the $\mathrm{CO}_{2}$ eq emissions in these conditions can increase up to $50 \%$ compared to emission in easy condition.

Higher variability in terms of chipping efficiency was recorded in difficult conditions of accessibility. These higher values were probably related to the higher OD, NOD and lower net productivity compared to easy and moderate accessibility. Analysing different chippers, Spinelli et al. [19] estimates, on average, total delay factor of $37.3 \%$ for chipping at the landing and $32.1 \%$ for chipping operation in the forest. Our results show higher efficiency for chipping operation in moderate conditions (70.91\%) and lower in easy and difficult conditions (67.91\% and $60.97 \%$ ). 


\section{Conclusion}

Chipping forest residues is considered an important economic and forest tending activity, besides the recovery of LQB after natural disturbances could reduce the risk of forest fires, diseases and pests [6]. Environmental impact of recovery and chipping LQB are challenging operations especially in mountainous conditions, where the quality of road infrastructures (e.g. steep gradient and turning radius), quantity and distance between biomass piles and distance from primary road network play an important role. Chipping in complex situations, as working sites along secondary forest road, lead an increase in term of $\mathrm{CO}_{2}$ eq emission and a reduction of chipping efficiency. Time spent and travel distance are higher inside difficult working sites. Quantity and position of piles should be planned before forest operations in order to favour the cooperation between the yarding contractor, chipping contractor and forest manager. Long term monitoring based on FMS has great potential and it is available for different truck-based models[17]. At present, additional information about wood quality and quantity need to be manually recorded by the operators and linked with machine activity parameters in order to better understanding productivity and efficiency of chipping activity and fuelwood supply chain.

Funding: This study is part of the CARE4C project found by EU Commission (GA 778322) and of the Young research for VAIA of the PhD LERH Program of the Università degli Studi di Padova in the frame of VAIA-Front project of TESAF Department.

Acknowledgments: We thank the contractors involved in this study

Conflicts of Interest: The authors declare no conflict of interest

\section{References}

1. Bais, A.L.S.; Lauk, C.; Kastner, T.; Erb, K. Global patterns and trends of wood harvest and use between 1990 and 2010. Ecological Economics 2015, 119, 326-337, doi:10.1016/j.ecolecon.2015.09.011.

2. European Commission The European Green Deal. Communication from the Commission to the European Parliament, the European Council, the Council, the European Economic and Social Committee and the Committee of the regions 2019, 1-30.

3. Petersen, A.K.; Solberg, B. Environmental and economic impacts of substitution between wood products and alternative materials: A review of micro-level analyses from Norway and Sweden. Forest Policy and Economics 2005, 7, 249-259, doi:10.1016/S1389-9341(03)00063-7.

4. Coyette, H.; Schenk, C. Agriculture, forestry and fishery statistics; Cook, E., Ed.; 2019th ed.; Eurostat: Luxemburg, 2019; ISBN 9789279330056.

5. Keegan, D.; Kretschmer, B.; Elbersen, B.; Panoutsou, C. Cascading use: a systematic approach to biomass beyond the energy sector. Biofuels, Bioproducts and Biorefining 2013, 7, 193-206, doi:10.1002/bbb.

6. Vance, E.D.; Prisley, S.P.; Schilling, E.B.; Tatum, V.L.; Wigley, T.B.; Lucier, A.A.; Van Deusen, P.C. Environmental implications of harvesting lower-value biomass in forests. Forest Ecology and Management 2018, 407, 47-56, doi:10.1016/j.foreco.2017.10.023.

7. Asikainen, A.; Routa, J.; Laitila, J.; Riala, M.; Prinz, R.; Stampfer, K.; Holzleitner, F.; Erber, G.; Kanzian, C.; Spinelli, R.; et al. Innovative, effective and sustainable technology and logistics for forest residual biomass; 2014;

8. Hytönen, J.; Moilanen, M. Effect of harvesting method on the amount of logging residues in the thinning of Scots pine stands. Biomass and Bioenergy 2014, 67, 347-353, doi:10.1016/j.biombioe.2014.05.004.

9. Spinelli, R.; Eliasson, L.; Han, H.S. A Critical Review of Comminution Technology and Operational Logistics of Wood Chips. Current Forestry Reports 2020, 6, 210-219, doi:10.1007/s40725-020-00120-9.

10. Spinelli, R.; Magagnotti, N.; Aminti, G.; De Francesco, F.; Lombardini, C. The effect of harvesting method on biomass retention and operational efficiency in low-value mountain forests. European Journal of Forest Research 2016, 135, 755764, doi:10.1007/s10342-016-0970-y.

11. Spinelli, R.; Nati, C.; Magagnotti, N. Recovering logging residue: Experiences from the Italian Eastern Alps. Croatian Journal of Forest Engineering 2007, 28, 1-9.

12. De la Fuente, T.; González-García, S.; Athanassiadis, D.; Nordfjell, T. Fuel consumption and GHG emissions of forest 
biomass supply chains in Northern Sweden: a comparison analysis between integrated and conventional supply chains. Scandinavian Journal of Forest Research 2017, 32, 568-581, doi:10.1080/02827581.2016.1259424.

13. Mihelič, M.; Spinelli, R.; Poj, A. Production of wood chips from logging residue under space-constrained conditions. Croatian Journal of Forest Engineering 2018, 39, 223-232.

14. Marchi, E.; Magagnotti, N.; Berretti, L.; Neri, F.; Spinelli, R. Comparing terrain and roadside chipping in mediterranean pine salvage cuts. Croatian Journal of Forest Engineering 2011, 32, 587-598.

15. Picchio, R.; Proto, A.R.; Civitarese, V.; Di Marzio, N.; Latterini, F. Recent Contributions of Some Fields of the Electronics in Development of Forest Operations Technologies. Electronics 2019, 8, 19, doi:10.3390/electronics8121465.

16. Deboli, R.; Ruggeri, M.; Calvo, A. A short supply chain to guarantee wood-chip quality. Applied Mathematical Sciences 2014, 8, 6589-6598, doi:10.12988/ams.2014.46440.

17. Holzleitner, F.; Kanzian, C.; Höller, N. Monitoring the chipping and transportation of wood fuels with a fleet management system. Silva Fennica 2013, 47, 1-11, doi:10.14214/sf.899.

18. Björheden, R.; Rickards, J.; Skaar, R.; Haberle, S.; Apel, K. Forest work-study nomenclature. Swedish University of Agricultural Sciences 1995, Garpennber, 22.

19. Spinelli, R.; Visser, R.J.M. Analyzing and estimating delays in wood chipping operations. Biomass and Bioenergy 2009, 33, 429-433, doi:10.1016/j.biombioe.2008.08.003.

(c)

(C) 2020 by the authors; licensee MDPI, Basel, Switzerland. This article is an open access article distributed under the terms and conditions of the Creative Commons Attribution (CC-BY) license (http://creativecommons.org/licenses/by/4.0/). 